\title{
IMPACTO DE HERBICIDAS NA BIOMASSA MICROBIANA E NOS MICRORGaNismos SOLUBILIZAdORES DE ORTOFOSFATO DO SOLO RIZOSFÉrICO DE CANA-DE-AÇÚCAR ${ }^{1}$
}

\author{
Impact of Herbicides on the Microbial Biomass and Orthophosphate-Solubilizing Microrganisms \\ in Rhizosferic Soil Grown with Sugarcane
}

\author{
TIRONI, S.P. ${ }^{2}$, REIS, M.R. ${ }^{2}$, SILVA, A.F. ${ }^{2}$, FERREIRA, E.A. ${ }^{2}$, BARBOSA, M.H.P. ${ }^{3}$, COSTA, M.D. ${ }^{4}$, \\ SILVA, A.A. ${ }^{3}$ e GALON, L. ${ }^{2}$
}

\begin{abstract}
RESUMO - Objetivou-se com este trabalho avaliar o carbono da biomassa microbiana (CBM), o potencial do solubilização de fosfato inorgânico (PSFI) e o potencial relativo de solubilização de fosfato inorgânico (PRSFI) do solo rizosférico de cultivares de cana-de-açúcar após a aplicação de herbicidas. O experimento foi conduzido em campo, no sistema de plantio convencional em delineamento de blocos casualizados, com quatro repetições. Os tratamentos foram constituídos pelos cultivares de cana-de-açúcar RB86-7515 e SP80-1816 e pelos herbicidas ametryn (2.000 $\left.\mathrm{g} \mathrm{ha}^{1}\right)$, trifloxysulfuron-sodium $\left(22,5 \mathrm{~g} \mathrm{ha}^{-1}\right)$, trifloxysulfuron-sodium + ametryn $\left(37,0+1.463 \mathrm{~g} \mathrm{ha}^{-1}\right)$ e sulfentrazone $\left(750 \mathrm{~g} \mathrm{ha}^{-1}\right)$, além de uma testemunha sem aplicação de herbicida. A aplicação dos herbicidas foi realizada quando a cultura se apresentava com três a quatro folhas. Aos 7, 14 e 28 dias após a aplicação dos herbicidas (DAH) foi coletado solo rizosférico da cultura e realizadas as avaliações do CBM, do PSFI e do PRSFI. O CBM do solo rizosférico do cultivar RB86-7515 foi menos influenciado pela aplicação dos herbicidas aos $7 \mathrm{DAH}$, em relação ao SP80-1816. O trifloxysulfuron-sodium estimulou o PSFI (21,11\%), enquanto o ametryn provocou redução deste, e o sulfentrazone pouco influenciou. Há diferenças entre cultivares de cana-de-açúcar na associação com microrganismos do solo, os quais apresentam resposta distinta com a aplicação de herbicidas.
\end{abstract}

Palavras-chave: solubilização de fosfato, fosfatase ácida, ametryn, trifloxysulfuron-sodium, sulfentrazone.

\begin{abstract}
This work aimed to evaluate soil microbial biomass carbon (MBC), phosphate solubilization potential (PSP), and relative phosphate solubilization potential (RPSP) in the rhizosphere soil of sugarcane cultivars after herbicide application. The trial was installed under field conditions in a conventional tillage system, using a completely randomized block design with four replications. The treatments corresponded to two sugarcane varieties, RB86-7515 and SP80-1816, and the

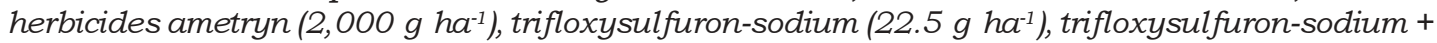
ametryn $\left(37+1,463 \mathrm{~g} \mathrm{ha}^{-1}\right)$, sulfentrazone $\left(750 \mathrm{~g} \mathrm{ha}^{-1}\right)$, and an untreated control plot. The herbicide was applied when plants presented 3 to 4 leaves. Soil samples were collected at 7, 14, and 28 days after herbicide application (DAH) for the MBC, PSIF, and RPSP evaluations. MBC in the rhizospheric soil of RB86-7515 was less affected by the herbicides at 7 DAH, compared to SP80-1816. Trifloxysulfuron-sodium stimulated PSIF (21.11\%), while ametryn reduced its activity. Sulfentrazone did not affect PSIF. The sugarcane varieties tested varied in their capacity to associate with soil microorganisms, resulting in different responses of the soil microbiota to the herbicides.
\end{abstract}

Keywords: phosphate solubilization, acid phosphatase, ametryn, trifloxysulfuron-sodium, sulfentrazone.

1 Recebido para publicação em 12.4.2009 e na forma revisada em 11.12.2009.

2 Engô-Agrọ , aluno do Programa de Pós-Graduação em Fitotecnia, Dep. de Fitotecnia, Universidade Federal de Viçosa - DFT/UFV,

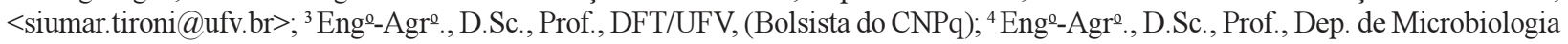
- DMB/UFV. 


\section{INTRODUÇÃO}

O Brasil vem se destacando no cenário mundial como produtor de biocombustiveis, a exemplo do biodiesel, produzido de grãos de plantas oleaginosas, como a soja, o dendê e a mamona, e principalmente do etanol de cana-de-açúcar (Embrapa, 2007). Essa última alternativa é considerada a melhor, do ponto de vista econômico, energético e ambiental, para a produção de álcool-combustivel (Andreoli \& Souza, 2006). O País tem potencial para suprir metade da demanda mundial de etanol, sendo necessário aumentar a produção da cana-de-açúcar e a eficiência do processo industrial de produção de álcool (Colombo, 2006).

A cultura da cana-de-açúcar exige grande quantidade de nutrientes, com predominância de nitrogênio $(\mathrm{N})$, potássio $(\mathrm{K})$ e fósforo $(\mathrm{P})$. Apesar de em menor quantidade, este último é o mais limitante para a produção agrícola em solos tropicais (Chien \& Menon, 1995), por se encontrar em formas pouco disponiveis às plantas, complexado com óxidos de ferro $(\mathrm{Fe})$ e alumínio (Al).

Para suprir as necessidades das plantas por P, são aplicados fertilizantes fosfatados nas lavouras. Contudo, grande parte desse elemento é rapidamente convertida em complexos insolúveis ou adsorvida pela fase sólida do solo, tornando-o indisponível às plantas (Vassilev \& Vassileva, 2003). O comportamento e a magnitude da complexação e adsorção do $\mathrm{P}$ aos componentes do solo são dependentes de pH (Yang et al., 2006), teores de óxidos (Fe e Al) e outros fatores que alteram o equilíbrio Pindisponivel/P-disponivel (Novais \& Smyth, 1999).

Os microrganismos são reconhecidos por sua habilidade em promover transformações bioquímicas dos nutrientes, disponibilizandoos às plantas (Moreira \& Siqueira, 2006). Os microrganismos solubilizadores de fosfato inorgânico (MSFI) possuem como principal mecanismo de solubilização de $\mathrm{P}$ a liberação de ácidos orgânicos, como o glucônico, o cítrico, o glutâmico, o oxálico, o lático, o fumárico, o tartárico e o succínico (Silva Filho et al., 2002). Esses ácidos orgânicos competem com o $\mathrm{P}$ pela ligação com óxidos de $\mathrm{Fe}$ e $\mathrm{Al}$, atuando como agentes quelantes dos íons $\mathrm{Ca}, \mathrm{Al}$ e $\mathrm{Fe}$, favorecendo a solubilização do fosfato inorgânico do solo (Rodríguez \& Fraga, 1999). Entre os microrganismos mais eficientes na solubilização de $\mathrm{P}$ inorgânico estão algumas estirpes de bactérias dos gêneros Pseudomonas, Bacillus e Rhizobium (Rodríguez \& Fraga, 1999) e fungos, com destaque para os gêneros Aspergillus e Penicillium (Silva Filho et al., 2002).

A diversidade e as populações dos MSFI são superiores em solos rizosféricos (Nahas et al., 1994; Nautiyal, 1999), devido ao maior aporte de carbono (C) e energia, fornecida via exsudação radicular das plantas (Moreira \& Siqueira, 2006). Isso resulta em maiores taxas de solubilização de P nos solos rizosféricos, em comparação aos não rizosféricos (Reis et al., 2008a).

No manejo da cana-de-açúcar é comum o uso de herbicidas para o controle de plantas daninhas (Christoffoleti et al., 2006). Essa cultura ocupa o segundo lugar no consumo de herbicidas no Brasil (SINDAG, 2008); a maioria desses herbicidas apresenta longo efeito residual no solo (Procópio et al., 2003).

Entre os herbicidas recomendados para a cana-de-açúcar, destacam-se o ametryn e o trifloxysulfuron-sodium, que atuam na inibição do fotossistema II e na enzima acetolactato sintase (ALS), respectivamente. Eles são comercializados também em mistura formulada, visando ampliar o espectro de controle de plantas daninhas; todavia, o comportamento desses produtos no ambiente ainda é pouco conhecido (Rodrigues \& Almeida, 2005). Dos diversos herbicidas utilizados na cana-deaçúcar, destaca-se também o sulfentrazone, que inibe a enzima protoporfirinogênio oxidase (PROTOX) (Silva et al., 2007). De modo geral, nos estudos com herbicidas tem-se dado ênfase apenas à eficiência no controle das plantas daninhas (Pires et al., 2005) e à seletividade à cultura (Galon, 2008), com poucos relatos sobre os efeitos na microbiota do solo.

Segundo Bunemann (2006), os herbicidas pouco afetam os organismos do solo. Entretanto, tem sido relatado que alguns desses produtos podem desequilibrar os ecossistemas edáficos e aquáticos (Das et al., 2003). Outras pesquisas demonstram efeitos da aplicação de herbicidas nas populações e atividade de microrganismos de solo (Santos et al., 2005; Vivian et al., 2006; Reis et al., 2008b), 
inclusive no potencial de solubilização de fósforo inorgânico (Reis et al., 2008a; Massenssini et al., 2008).

Com a expansão do cultivo da cana-deaçúcar no Brasil, torna-se necessário avaliar com maior frequência os impactos das práticas de manejo adotadas com a cultura, entre elas a aplicação de herbicidas. Assim, objetivou-se com este trabalho avaliar o carbono da biomassa microbiana (CBM), o potencial de solubilização de fosfato inorgânico (PSFI) e o potencial relativo de solubilização de fosfato inorgânico do solo rizosférico de cultivares de cana-de-açúcar após a aplicação dos herbicidas trifloxysulfuron-sodium, ametryn, trifloxysulfuron-sodium + ametryn e sulfentrazone.

\section{MATERIAL E MÉTODOS}

O experimento foi conduzido na Estação Experimental da Horta Nova (distrito de São José do Triunfo), pertencente à Universidade Federal de Viçosa (UFV), município de ViçosaMG, em um Argissolo Vermelho-Amarelo (Embrapa, 2006). O plantio da cana-de-açúcar foi realizado em sistema convencional, com aração e gradagens, com posterior sulcamento da área, em distância entre linhas de 1,4 m. A densidade de plantio foi de 18 gemas $\mathrm{m}^{-1}$. A adubação foi realizada no sulco de plantio, de acordo com resultados da análise do solo (Tabela 1) e recomendações para cultura (CFSEMG, 1999), utilizando $500 \mathrm{~kg} \mathrm{ha}^{-1}$ da formulação NPK 8-28-16, mais adubação de cobertura com aplicação de $160 \mathrm{~kg} \mathrm{ha}^{-1}$ de cloreto de potássio.
O delineamento experimental foi em blocos casualizados, com quatro repetições; as unidades experimentais foram constituídas de seis linhas $(8,4 \mathrm{~m})$ de $3,0 \mathrm{~m}$ de comprimento, com área total de $25,2 \mathrm{~m}^{2}$. Os tratamentos foram alocados em esquema fatorial $(2 \times 5)$, sendo o fator A composto pelos cultivares de canade-açúcar RB86-7515 e SP80-1816, e o fator B, pelos herbicidas Metrimex $500 \mathrm{SC}^{\circledR}$ (ametryn - $2.000 \mathrm{~g} \mathrm{ha}^{-1}$ ), Envoke ${ }^{\circledR}$ (trifloxysulfuronsodium - 22,5 $\mathrm{g} \mathrm{ha}^{-1}$ ), Krismat ${ }^{\circledR}$ (trifloxysulfuron-sodium + ametryn - 37,0 + $\left.1.463 \mathrm{~g} \mathrm{ha}^{-1}\right)$ e Boral 500 SC$^{\circledR}$ (sulfentrazone $-750 \mathrm{~g} \mathrm{ha}^{-1}$ ) e mais uma testemunha sem aplicação de herbicida.

A aplicação dos herbicidas foi realizada em pós-emergência, quando a cultura se encontrava com três a quatro folhas completamente expandidas, com pulverizador costal pressurizado a $\mathrm{CO}_{2}$, munido de barra de $1,5 \mathrm{~m}$ com três pontas de aplicação da série TT 110.02, espaçadas de 0,5 m, calibrado para aspergir o volume de $150 \mathrm{~L} \mathrm{ha}^{-1}$ de calda herbicida.

Aos 7, 14 e 28 dias após a aplicação dos herbicidas (DAH) foi coletado solo rizosférico da cultura. Para isso, as plantas foram arrancadas e o sistema radicular submetido à agitação, considerando solo rizosférico o que ficou aderido às raízes. As amostras de solo foram levadas ao laboratório, para realização das avaliações do carbono da biomassa microbiana (CBM) (Vance et al., 1987, modificado por Islam \& Weil, 1998) e do potencial de solubilização de fosfato inorgânico (PSFI) (Nautyal, 1999).

Tabela 1 - Características químicas e físicas do solo, de amostras coletadas de 0 a $10 \mathrm{~cm}$ de profundidade, de lavouras de cana-deaçúcar (cana-planta), em estádio vegetativo com três folhas completamente expandidas. Viçosa-MG, 2008

\begin{tabular}{|c|c|c|c|c|c|c|c|c|c|c|c|c|}
\hline \multicolumn{13}{|c|}{ Características químicas $^{1 /}$} \\
\hline $\mathrm{pH}$ & $\mathrm{P}$ & $\mathrm{K}^{+}$ & $\mathrm{Ca}^{2+}$ & $\mathrm{Mg}^{2+}$ & $\mathrm{Al}^{3+}$ & $\mathrm{H}+\mathrm{Al}$ & SB & CTC(t) & CTC (T) & $\mathrm{V}$ & $\mathrm{m}$ & $\mathrm{MO}$ \\
\hline$\left(\mathrm{H}_{2} \mathrm{O}\right)$ & \multicolumn{2}{|c|}{$\left(\mathrm{mg} \mathrm{dm}^{-3}\right)$} & \multicolumn{7}{|c|}{$\left(\mathrm{cmol}_{\mathrm{c}} \mathrm{dm}^{-3}\right)$} & \multicolumn{2}{|c|}{$\%$} & $\left(\right.$ dag kg $\left.{ }^{-1}\right)$ \\
\hline 6,0 & 7,4 & 168 & 4,2 & 0,7 & 0,0 & 4,46 & 5,33 & 5,33 & 9,79 & 54 & 0 & 2,4 \\
\hline \multicolumn{13}{|c|}{ Características físicas $^{1 /}$} \\
\hline & & & Silte & & grossa & & a fina & \multirow{2}{*}{\multicolumn{5}{|c|}{ Classificação textural }} \\
\hline \multicolumn{8}{|c|}{$(\%)$} & & & & & \\
\hline & & & 32 & & 7 & & 4 & \multicolumn{5}{|c|}{ Argiloso } \\
\hline
\end{tabular}

1/ Análise realizada no Laboratório de Análise de Solos Viçosa Ltda; CTC (T): capacidade da troca de cátions (pH 7); CTC (t): capacidade de troca de cátions efetiva; V: saturação de bases; m: saturação de alumínio; MO: matéria orgânica. 
Para determinação do CBM, foram retiradas duas porções de solo de cada amostra (18 g), sendo uma submetida à radiação de microondas por tempo previamente calculado $(60 \mathrm{~s}+60 \mathrm{~s})$, substituindo a fumigação com clorofórmio (Islam \& Weil, 1998). Foram adicionados às amostras de solo $80 \mathrm{~mL}$ de $\mathrm{K}_{2} \mathrm{SO}_{4}$ 0,5 $\mathrm{mol} \mathrm{L}^{-1}$, agitando-se em seguida a $200 \mathrm{rpm}$ por 30 minutos em mesa agitadora horizontal. As amostras permaneceram em repouso por mais 30 minutos, para decantação do solo. Em seguida, a fase superior foi filtrada em papel-filtro Whatman $\mathrm{n}^{-}$42. Dez $\mathrm{mL}$ do filtrado foram colocados em tubos digestores, adicionando-se os seguintes reagentes: $2 \mathrm{~mL}$ de solução $\mathrm{K}_{2} \mathrm{Cr}_{2} \mathrm{O}_{7} 0,0667 \mathrm{~mol} \mathrm{~L}^{-1}, 5 \mathrm{~mL}$ de $\mathrm{H}_{3} \mathrm{PO}_{4}$ concentrado e $10 \mathrm{~mL}$ de $\mathrm{H}_{2} \mathrm{SO}_{4}$ concentrado. Após esfriar, esta solução foi completada para $100 \mathrm{~mL}$ com água destilada e adicionado o indicador de difenilamina (seis gotas), procedendo em seguida à titulação com solução $0,0333 \mathrm{~mol} \mathrm{~L}^{-1} \mathrm{de}\left(\mathrm{NH}_{4}\right)_{2} \mathrm{Fe}\left(\mathrm{SO}_{4}\right)_{2}$ até a mudança de coloração para vermelho-tijolo. O CBM foi estimado pela diferença entre a amostra irradiada e a não irradiada (Vance et al., 1987; Islam \& Weil, 1998).

Para avaliação do PSFI do solo em meio liquido, transferiu-se $1 \mathrm{~g}$ de solo de cada amostra para tubo de ensaio com $15 \mathrm{~mL}$ do meio líquido NBRI, $\mathrm{pH}$ 6,8-7,0, contendo $\left(\mathrm{g} \mathrm{L}^{-1}\right)$ : glicose, $10 ; \mathrm{Ca}_{3}\left(\mathrm{PO}_{4}\right)_{2}, 5 ; \mathrm{MgCl}_{2} \cdot 6 \mathrm{H}_{2} \mathrm{O}, 0,5$; $\mathrm{MgSO}_{4} .7 \mathrm{H}_{2} \mathrm{O}, 0,25 ; \mathrm{KCl}, 0,2 ; \mathrm{e}\left(\mathrm{NH}_{4}\right)_{2} \mathrm{SO}_{4}, 0,1$ (Nautyal, 1999). Os tubos foram incubados por 15 dias a $30^{\circ} \mathrm{C}$, sendo, então, retiradas aliquotas de $1,5 \mathrm{~mL}$ do sobrenadante para análise da concentração de $\mathrm{P}$. As alíquotas foram centrifugadas a $8.000 \mathrm{rpm}$ por 20 minutos, sendo retirado $1 \mathrm{~mL}$ do sobrenadante para determinação do $\mathrm{P}$ inorgânico pelo método colorimétrico da vitamina $\mathrm{C}$ modificado, a $725 \mathrm{~nm}$ (Braga \& Defelipo, 1974). Com os resultados do PSFI e do CBM, foi calculado o potencial de solubilização relativa de fosfato inorgânico, representado pela quantidade de fosfato inorgânico solubilizada por unidade de CBM (Reis et al., 2008b).

A determinação da atividade da enzima fosfomonoesterase ácida foi realizada usandose o método descrito por Tabatabai $\&$ Bremmer (1969). Um g de solo e 0,2 $\mathrm{mL}$ de tolueno foram transferidos para tubo de ensaio com $4 \mathrm{~mL}$ da solução-tampão ácida (pH 6,5), composta de:
$12,1 \mathrm{~g}$ de tris(hidroximetil)aminometano (THAM), 11,6 g de ácido maleico, 14,0 g de ácido cítrico, 6,3 g de ácido bórico e $20 \mathrm{~g}$ de hidróxido de sódio por litro de solução. Foi adicionado aos tubos $1 \mathrm{~mL}$ da solução de $p$-nitrofenilfosfato dissódico tetraidratado $\left(\mathrm{C}_{6} \mathrm{H}_{4} \mathrm{NNaO}_{6} \mathrm{P} .4 \mathrm{H}_{2} \mathrm{O}\right), 0,05 \mathrm{moL} \mathrm{L}^{-1}$, usada como substrato para a enzima. Os tubos foram incubados por uma hora a $37^{\circ} \mathrm{C}$. Após a incubação, adicionaram-se $1 \mathrm{~mL}$ de $\mathrm{CaCl}_{2}$ $0,5 \mathrm{moL} \mathrm{L}^{-1}$ e $4 \mathrm{~mL}$ de $\mathrm{NaOH} 0,5 \mathrm{moL} \mathrm{L}^{-1}$, submetendo-os à agitação e filtragem lenta em papel-filtro. A concentração de $p$-nitrofenol foi quantificada no filtrado, em leitura de absorbância a $420 \mathrm{~nm}$, utilizando como referência uma curva-padrão de concentração de $p$-nitrofenilfosfato conhecida, sendo expressa em $\mu \mathrm{g} p$-nitrofenol $\mathrm{g}^{-1}$ solo $\mathrm{h}^{-1}$.

Os resultados das avaliações foram submetidos à análise de variância. Quando necessário, as médias dos tratamentos foram comparadas pelo teste de Duncan a 5\% de probabilidade.

\section{RESULTADOS E DISCUSSÃO}

Os tratamentos apresentaram interação, isto é, a resposta dos fatores teve influência da ação conjunta dos tratamentos para as variáveis CBM aos 7, PSFI aos 7 e 28 e PSRFI aos 7 dias após a aplicação dos herbicidas (DAH).

O cultivar RB86-7515 apresentou maior CBM no solo rizosférico quando tratado com sulfentrazone aos 7 DAH (Tabela 2). A maior estabilidade da biomassa microbiana, nesse caso, pode estar associada à maior tolerância do cultivar a herbicidas (Ferreira et al., 2005; Galon, 2008).

Quanto ao cultivar SP80-1816, os tratamentos em que se aplicou o ametryn isolado ou em mistura com o trifloysulfuron-sodium apresentaram maior redução do $\mathrm{CBM}$, em relação à testemunha sem aplicação. Esses resultados concordam com os encontrados por Reis et al. (2008b), ao observarem maior redução da CBM no solo rizosférico da canade-açúcar cultivada em ambiente protegido, após a aplicação dos mesmos herbicidas. Os referidos efeitos podem ser atribuídos à toxicidade dos componentes inertes da formulação 
comercial do ametryn, aplicado nas doses recomendadas de 5 a $6 \mathrm{~L} \mathrm{ha}^{-1}$ da formulação comercial (Agrofit, 2008). Santos et al. (2004), ao avaliarem o impacto de diferentes formulações de glyphosate, observaram que os maiores efeitos tóxicos são causados por compostos presentes na formulação e não pelo princípio ativo do herbicida.

Os herbicidas podem ocasionar efeitos distintos sobre os microrganismos do solo. Mahía et al. (2008) evidenciaram que o atrazine apresentou efeitos distintos em diferentes tipos de solo. Esses autores observaram incremento do CBM em solos com maior e redução em solos com menor teor de matéria orgânica, porém, em ambos, ocorreu aumento da mineralização do carbono orgânico do solo, resultado da maior atividade microbiana. Jakelaitis et al. (2007) não observaram efeitos tóxicos aos microrganismos do solo cultivando milho após a aplicação de atrazine e nicosulfuron - herbicidas pertencente aos grupos dos inibidores do fotossistema II e da enzima acetolactato sintase, respectivamente.

Entre os cultivares não foi observada diferença nos tratamentos com herbicidas, exceto para o sulfentrazone, que provocou aumento do CBM no cultivar RB86-7515 (Tabela 2). Esse fato pode estar relacionado a efeitos fitotóxicos causados pelos hebicidas, podendo aumentar a exsudação radicular e, consequentemente, beneficiando a microbiota presente na rizosfera da cana-de-açúcar. Considerando que o sulfentrazone apresenta pouca mobilidade na planta e baixa mobilidade em solo argiloso (Rossi et al., 2005; Vivian et al., 2006), provavelmente ele não atingiu a região da rizosfera da cultura, não vindo a interferir diretamente na atividade microbiana da rizosfera. As maiores sintese e exsudação radiculares de aminoácidos e açúcares normalmente são influenciadas pelas condições de estresse (Bertin et al., 2003), como temperaturas extremas, seca e exposição aos raios ultravioleta (Pramanik et al., 2000). Infere-se, portanto, que o estresse provocado pelo herbicida pode influenciar na composição e no volume dos exsudatos radiculares da cana-deaçúcar.

Nas avaliações aos 14 e 28 DAH não foram observadas diferenças entre os cultivares para o CBM, somente havendo diferenças entre os tratamentos com herbicidas aos $14 \mathrm{DAH}$ (Tabela 3). Foi observado maior valor de CBM no tratamento com trifloxysulfuron-sodium, herbicida este que apresenta mobilidade na planta (sistêmico) (Silva et al., 2007). Um dos processos de destoxificação realizado pelas plantas é a eliminação dos herbicidas pelo sistema radicular, aumentando o volume de exsudato e o montante de carbono metabolizável pelos microrganismos, possibilitando o aumento da população microbiana do solo.

Menores valores de CBM foram observados nos tratamentos com aplicação do ametryn

Tabela 2 - Valores médios do carbono da biomassa microbiana (CBM) do solo rizosférico de cana-de-açúcar ( $\mu \mathrm{g} \mathrm{CBMg}^{-1}$ solo), amostrado na camada de 3 a $10 \mathrm{~cm}$, em função de cultivares e herbicidas, aos 7 dias após a aplicação dos herbicidas. Viçosa-MG, 2008

\begin{tabular}{|l|l|c|}
\hline \multirow{2}{*}{\multicolumn{1}{|c|}{ Tratamento }} & \multicolumn{1}{|c|}{ CBM ( $\mathrm{g} \mathrm{CBM} \mathrm{g}^{-1}$ solo $)$} \\
\cline { 2 - 3 } & SP80-1816 & RB86-7515 \\
\hline Testemunha sem herbicida & $203,06 \mathrm{aA}^{1 /}$ & $156,96 \mathrm{bA}$ \\
\hline Trifloxysulfuron-sodium & $159,10 \mathrm{abcA}$ & $126,38 \mathrm{bA}$ \\
\hline Ametryn & $107,57 \mathrm{cB}$ & $171,50 \mathrm{bA}$ \\
\hline Trifloxysulfuron-sodium + ametryn & $137,43 \mathrm{bcA}$ & $148,30 \mathrm{bA}$ \\
\hline Sulfentrazone & $175,63 \mathrm{abB}$ & $230,28 \mathrm{aA}$ \\
\hline CV (\%) & \multicolumn{2}{|c|}{21,80} \\
\hline
\end{tabular}

1/ Médias seguidas de mesmas letras, minúsculas nas colunas e maiúsculas nas linhas, não diferem entre si pelo teste de Duncan e $\mathrm{F}$, respectivamente, a $5 \%$ de probabilidade.

Tabela 3 - Valores médios do carbono da biomassa microbiana do solo rizosférico de cana-de-açúcar, amostrado na camada de 3 a $10 \mathrm{~cm}$, em função de cultivares e herbicidas, aos 14 e 28 dias após a aplicação dos herbicidas. Viçosa-MG, 2008

\begin{tabular}{|l|c|c|}
\hline \multirow{2}{*}{\multicolumn{1}{|c|}{ Tratamento }} & \multicolumn{2}{c|}{$\begin{array}{c}\text { CBM } \\
\left(\mathrm{g} \mathrm{CBM} \mathrm{g}^{-1} \text { solo }\right)\end{array}$} \\
\cline { 2 - 3 } & $14 \mathrm{DAH}^{1 /}$ & $28 \mathrm{DAH}$ \\
\hline Testemunha sem herbicida & $176,63 \mathrm{~b}^{2 /}$ & $129,74 \mathrm{a}$ \\
\hline Trifloxysulfuron-sodium & $210,96 \mathrm{a}$ & $145,59 \mathrm{a}$ \\
\hline Ametryn & $120,16 \mathrm{c}$ & $125,80 \mathrm{a}$ \\
\hline Trifloxysulfuron-sodium + ametryn & $136,77 \mathrm{c}$ & $140,17 \mathrm{a}$ \\
\hline Sulfentrazone & $170,98 \mathrm{~b}$ & $146,31 \mathrm{a}$ \\
\hline SP80-1816 & $165,39 \mathrm{a}$ & $133,20 \mathrm{a}$ \\
\hline RB86-7515 & $160,81 \mathrm{a}$ & $141,84 \mathrm{a}$ \\
\hline CV (\%) & 18,47 & 18,57 \\
\hline
\end{tabular}

1/Dias após a aplicação dos herbicidas; ${ }^{2 /}$ Médias seguidas da mesma letra na coluna não diferem entre si pelo teste de Duncan para os tratamentos com herbicidas e F para os cultivares, a 5\% de probabilidade. 
isolado ou em mistura aos $14 \mathrm{DAH}$, como verificado aos 7 DAH (Tabela 3). Entretanto, o sulfentrazone não mais apresentou influência nessa variável. Segundo Vieira et al. (2007), esse produto promoveu redução da biomassa microbiana do solo cultivado com soja até 46 DAH e, em aplicação sobre a cana-de-açúcar, levou à redução do CBM, após duas aplicações, aos 197 e 640 DAH (Vivian et al., 2006). Moreno et al. (2007) atribuíram o aumento do CBM após a aplicação do herbicida atrazine à adaptação dos microrganismos, utilizando o composto como fonte de carbono e energia. Esses efeitos são pouco prováveis para o trifloxysulfuron-sodium, devido à baixa dose aplicada, como observado para o metsulfuronmethyl, também inibidor da ALS, que em dose de até dez vezes maior que a recomendada não apresentou influência sobre os microrganismos do solo (Zabaloy et al., 2007).

Aos 28 DAH não foi observada influência dos cultivares e herbicidas no CBM do solo rizosférico (Tabela 3), evidenciando a resiliência dos microrganismos do solo.

Observou-se maior PSFI no solo rizosférico do cultivar RB86-7515 sem aplicação de herbicida, demonstrando maior associação do cultivar com os microrganismos solubilizadores de fosfato inorgânico do solo (Tabela 4). Nos tratamento com herbicidas foram obtidos maiores valores com aplicação do trifloxysulfuron-sodium no cultivar SP80-1816 e do trifloxysulfuron-sodium + ametryn no RB86-7515, demonstrando haver interação distinta entre cultivares e herbicidas.

Considerando o efeito dos herbicidas, o cultivar SP80-1816, na presença de trifloxysulfuron-sodium, apresentou maiores valores de PSFI (Tabela 4). Esses resultados concordam com os encontrados por Reis et al. (2008a), em que o trifloxysulfuron-sodium estimulou o PSFI do solo rizosférico de canade-açúcar, porém sem apresentar alterações na biomassa microbiana. Esses efeitos podem ser atribuídos à maior exsudação radicular da cultura como resposta aos efeitos fisiológicos provocados pelo herbicida (Shaw \& Burns, 2004), o que possibilita maior eficiência dos microrganismos na solubilização de fosfato inorgânico. Essa eficiência é influenciada pela qualidade do carbono orgânico disponibilizado para os microrganismos (Barroso et al., 2006).
Tabela 4 - Valores médios do potencial de solubilização de fosfato inorgânico (PFSI) do solo rizosférico de cana-de-açúcar ( $\mu \mathrm{g} \mathrm{P} \mathrm{g}{ }^{-1}$ solo), amostrado na camada de 3 a $10 \mathrm{~cm}$, em função de cultivares e herbicidas, aos 7 dias após aplicação dos herbicidas. Viçosa-MG, 2008

\begin{tabular}{|l|l|l|}
\hline \multirow{2}{*}{\multicolumn{1}{|c|}{ Tratamento }} & \multicolumn{2}{c|}{ PSFI ( $\mathrm{g} \mathrm{P} \mathrm{g}^{-1}$ solo $)$} \\
\cline { 2 - 3 } & SP80-1816 & RB86-7515 \\
\hline Testemunha sem herbicida & $28,81 \mathrm{bcB}^{-1}$ & $38,96 \mathrm{aA}$ \\
\hline Trifloxysulfuron-sodium & $39,13 \mathrm{aA}$ & $33,00 \mathrm{bcB}$ \\
\hline Ametryn & $23,68 \mathrm{cA}$ & $27,19 \mathrm{dA}$ \\
\hline Trifloxysulfuron-sodium + ametryn & $27,46 \mathrm{bcB}$ & $35,38 \mathrm{abA}$ \\
\hline Sulfentrazone & $30,10 \mathrm{bA}$ & $29,33 \mathrm{cdA}$ \\
\hline CV $(\%)$ & \multicolumn{2}{|c|}{11,57} \\
\hline
\end{tabular}

$1 /$ Médias seguidas de mesmas letras, minúsculas nas colunas e maiúsculas nas linhas, não diferem entre si pelo teste de Duncan e $\mathrm{F}$, respectivamente, a $5 \%$ de probabilidade.

$\mathrm{O}$ ametryn isolado ou em mistura com trifloxysulfuron-sodium reduziu os valores de solubilização. Esse efeito pode ser atribuído à toxicidade desse composto para a microbiota do solo (Reis et al., 2008a). Para o cultivar RB86-7515, os maiores valores de solubilização foram observados na testemunha e com aplicação do trifloxysulfurom-sodium + ametryn, e os menores, com aplicação de ametryn e sulfentrazone (Tabela 4). Os efeitos tóxicos dos herbicidas na atividade microbiana do solo podem ser diretos, apresentando toxicidade para a microbiota, ou indiretos, causando danos à cultura, os quais, por efeitos fisiológicos, reduzem a interação com os microrganismos. Arruda et al. (2001) observaram redução na nodulação radicular e nos aminoácidos exsudados pelo xilema da soja após a aplicação do herbicida sulfentrazone. Esse composto também influencia negativamente a associação da cultura com fungos micorrízicos (Vieira et al., 2007).

Aos $14 \mathrm{DAH}$, não se observou diferença entre os cultivares para o PSFI (Tabela 5). Os herbicidas não diferiram da testemunha, porém diferiram entre si, e a mistura comercial (trifloxysulfurom-sodium + ametryn) resultou em menores valores de PSFI. Efeitos sinergísticos da mistura de herbicidas podem ocorrer, ocasionando maior efeito de toxicidade. Santos et al. (2005) verificaram que a mistura de fluazifop-p-butil + fomesafen influenciou a biomassa microbiana do solo cultivado com feijão de forma distinta com relação à aplicação dos herbicidas separadamente. 
Aos 28 DAH, observaram-se efeitos de interação entre os cultivares e herbicidas sobre o PSFI (Tabela 6). Os efeitos dos herbicidas sobre o cultivar SP80-1816 foram semelhantes aos observados aos 7 DAH. Entretanto, o sulfentrazone não mais apresentou efeitos negativos sobre o PSFI, ocorrendo diminuição dos efeitos da toxicidade do herbicida sobre os microrganismos solubilizadores. Para o RB86-7515, os tratamentos com herbicidas não diferiram da testemunha. No entanto, entre os herbicidas, os maiores valores de PSFI foram observados nos tratamentos com o trifloxysulfuron-sodium + ametryn (Tabela 6). Esses efeitos, a longo prazo, podem ser atribuídos a mudanças na composição das comunidades microbianas do solo em função da influência dos herbicidas. Reis et al. (2008b) relataram a ocorrência de mudanças nas proporções populacionais da comunidade microbiana do solo rizosférico de cana-deaçúcar após a aplicação dos referidos herbicidas. O PSFI da microbiota do solo varia com os fatores nutricionais do meio, a exemplo da fonte de nitrogênio. A presença de amônio favoreceu a solubilização e a do nitrato diminuiu a atividade solubilizadora, reduzindo ou inibindo a liberação de ortofosfato na solução (Silva Filho \& Vidor, 2001).

O potencial de solubilização relativa de fosfato inorgânico (PSRFI) foi influenciado pelos cultivares e pelos herbicidas aos $7 \mathrm{DAH}$ (Tabela 7). O cultivar RB86-7515 mostrou maior solubilização relativa, apresentando maior potencial ou eficiência da população de microrganismos solubilizadores de fosfato associada a ela, em relação ao SP80-1816, no tratamento sem herbicida.

De modo geral, de ambos os cultivares, o trifloxysulfuron-sodium apresentou maior valor para o PSRFI (Tabela 7). As menores taxas de solubilização relativa foram observadas na testemunha e com o sulfentrazone para o cultivar SP80-1816, e com o ametryn e o sulfentrazone para o cultivar RB86-7515. As alterações do PRSFI podem estar diretamente relacionadas às proporções e espécies constituintes da população microbiana; assim, qualquer alteração na comunidade, seja por influência de cultivares ou de herbicidas, pode afetar essa característica.
Tabela 5 - Valores médios do potencial de solubilização de fosfato inorgânico (PSFI) do solo rizosférico de cana-de-açúcar, amostrado na camada de 3 a $10 \mathrm{~cm}$, em função de cultivares e herbicidas, aos 14 dias após a aplicação dos herbicidas. Viçosa-MG, 2008

\begin{tabular}{|l|l|}
\hline \multirow{2}{*}{ Tratamento } & PSFI $\left(\mathrm{g} \mathrm{P} \mathrm{g}^{-1}\right.$ solo $)$ \\
\cline { 2 - 2 } & $14 \mathrm{DAH}^{1 /}$ \\
\hline Testemunha sem herbicida & $25,76 \mathrm{ab}^{2 /}$ \\
\hline Trifloxysulfuron-sodium & $31,20 \mathrm{a}$ \\
\hline Ametryn & $26,02 \mathrm{ab}$ \\
\hline Trifloxysulfuron-sodium + ametryn & $22,36 \mathrm{~b}$ \\
\hline Sulfentrazone & $30,24 \mathrm{a}$ \\
\hline SP80-1816 & $28,00 \mathrm{a}$ \\
\hline RB86-7515 & $26,23 \mathrm{a}$ \\
\hline CV $(\%)$ & 18,19 \\
\hline
\end{tabular}

1/Dias após a aplicação dos herbicidas; ${ }^{2}$ Médias seguidas da mesma letra na coluna não diferem entre si pelo teste de Duncan para os tratamentos com herbicidas e $\mathrm{F}$ para os cultivares, a $5 \%$ de probabilidade.

Tabela 6 - Valores médios do potencial de solubilização de fosfato inorgânico do solo rizosférico de cana-de-açúcar ( $\mu \mathrm{g} \mathrm{P} \mathrm{g}{ }^{1}$ solo), amostrado na camada de 3 a $10 \mathrm{~cm}$, em função de cultivares e herbicidas, aos 28 dias após aplicação dos herbicidas. Viçosa-MG, 2008

\begin{tabular}{|l|l|l|}
\hline \multirow{2}{*}{ Tratamento } & \multicolumn{2}{|c|}{ PSFI ( $\mathrm{g} \mathrm{P} \mathrm{g}^{-1}$ solo $)$} \\
\cline { 2 - 3 } & SP80-1816 & RB86-7515 \\
\hline Testemunha sem herbicida & $19,84 \mathrm{bcA}^{\frac{1}{1}}$ & $21,23 \mathrm{abA}$ \\
\hline Trifloxysulfuron-sodium & $25,39 \mathrm{aA}$ & $19,57 \mathrm{bB}$ \\
\hline Ametryn & $17,06 \mathrm{cA}$ & $19,05 \mathrm{bA}$ \\
\hline Trifloxysulfuron-sodium + ametryn & $17,71 \mathrm{cB}$ & $24,28 \mathrm{aA}$ \\
\hline Sulfentrazone & $22,67 \mathrm{abA}$ & $23,38 \mathrm{abA}$ \\
\hline CV (\%) & \multicolumn{2}{|c|}{13,62} \\
\hline
\end{tabular}

1/ Médias seguidas de mesmas letras, minúsculas nas colunas e maiúsculas nas linhas, não diferem entre si pelo teste de Duncan e $\mathrm{F}$, respectivamente, a $5 \%$ de probabilidade.

Tabela 7 - Valores médios do potencial de solubilização relativa de fosfato inorgânico (PSRFI) de microrganismos da rizosfera da cana-de-açúcar ( $\left.\mu \mathrm{g} \mathrm{P} \mathrm{g}{ }^{-1} \mathrm{CBM}\right)$, amostrado na camada de 3 a $10 \mathrm{~cm}$, em função de cultivares e herbicidas, aos 7 dias após a aplicação dos herbicidas. Viçosa-MG, 2008

\begin{tabular}{|l|l|l|}
\hline \multirow{2}{*}{ Tratamento } & \multicolumn{2}{|c|}{ PSRFI $\left(\mathrm{g} \mathrm{P} \mathrm{g}^{-1} \mathrm{CBM}\right)$} \\
\cline { 2 - 3 } & SP80-1816 & RB86-7515 \\
\hline Testemunha sem herbicida & $146,06 \mathrm{bB}^{1 /}$ & $253,36 \mathrm{aA}$ \\
\hline Trifloxysulfuron-sodium & $250,82 \mathrm{aA}$ & $265,18 \mathrm{aA}$ \\
\hline Ametryn & $221,05 \mathrm{abA}$ & $169,01 \mathrm{bA}$ \\
\hline Trifloxysulfuron-sodium + ametryn & $215,40 \mathrm{abA}$ & $254,57 \mathrm{aA}$ \\
\hline Sulfentrazone & $173,07 \mathrm{bA}$ & $129,02 \mathrm{bA}$ \\
\hline CV (\%) & \multicolumn{2}{|c|}{23,20} \\
\hline
\end{tabular}

1/ Médias seguidas de mesmas letras, minúsculas nas colunas e maiúsculas nas linhas, não diferem entre si pelo teste de Duncan e $\mathrm{F}$, respectivamente, a $5 \%$ de probabilidade. 
O PRSFI não foi influenciado pelos cultivares nas avaliações aos 14 e $28 \mathrm{DAH}$ (Tabela 8). O uso de herbicidas apresentou efeito somente aos $14 \mathrm{DAH}$, e as maiores taxas foram observadas para o ametryn. Aos $28 \mathrm{DAH}$, não houve alterações no PRSFI entre os tratamentos com herbicidas, evidenciando a recuperação das populações microbianas.

Tabela 8 - Valores médios do potencial de solubilização relativa de fosfato inorgânico (PSRFI) de microrganismos da rizosfera da cana-de-açúcar, amostrado na camada de 3 a $10 \mathrm{~cm}$, em função de cultivares e herbicidas, aos 14 e 28 dias após a aplicação dos herbicidas. Viçosa-MG, 2008

\begin{tabular}{|l|c|c|}
\hline \multirow{2}{*}{ Tratamento } & \multicolumn{2}{|c|}{ PSRFI $\left(\mathrm{g} \mathrm{P} \mathrm{g}^{-1} \mathrm{CBM}\right)$} \\
\cline { 2 - 3 } & $14 \mathrm{DAH}^{1 /}$ & $28 \mathrm{DAH}$ \\
\hline Testemunha sem herbicida & $152,14 \mathrm{~b}^{2 /}$ & $169,30 \mathrm{a}$ \\
\hline Trifloxysulfuron-sodium & $148,39 \mathrm{~b}$ & $158,21 \mathrm{a}$ \\
\hline Ametryn & $231,74 \mathrm{a}$ & $146,85 \mathrm{a}$ \\
\hline Trifloxysulfuron-sodium + ametryn & $168,87 \mathrm{~b}$ & $156,20 \mathrm{a}$ \\
\hline Sulfentrazone & $183,75 \mathrm{ab}$ & $161,34 \mathrm{a}$ \\
\hline SP80-1816 & $176,96 \mathrm{a}$ & $161,44 \mathrm{a}$ \\
\hline RB86-7515 & $177,00 \mathrm{a}$ & $155,32 \mathrm{a}$ \\
\hline CV $(\%)$ & 27,08 & 24,30 \\
\hline
\end{tabular}

${ }^{1 /}$ Dias após a aplicação dos herbicidas; ${ }^{2 /}$ Médias seguidas da mesma letra na coluna não diferem entre si pelo teste de Duncan para os tratamentos com herbicidas e $\mathrm{F}$ para os cultivares, a 5\% de probabilidade.

Com base no exposto, conclui-se que a biomassa e a atividade da microbiota do solo são influenciadas pelos cultivares de cana-deaçúcar e pelos herbicidas aplicados sobre a cultura. Para a variável CBM, o cultivar RB867515 foi o menos influenciado pela aplicação dos herbicidas. O trifloxysulfurom-sodium estimulou o PSFI, enquanto o ametryn o reduziu. O PRSFI foi afetado de modo distinto pelos herbicidas e cultivares.

\section{AGRADECIMENTOS}

Ao Conselho Nacional de Desenvolvimento Científico e Tecnológico (CNPq), pelas concessões de bolsas e pelo apoio financeiro para a realização da pesquisa.

\section{LITERATURA CITADA}

AGROFIT. Sistema de Agrotóxicos Fitossanitários. 2008. Disponível em: <http://extranet.agricultura.gov.br/ agrofit>. Acesso em: 21 de dez de 2008
ANDREOLI, C.; DE SOUZA, S. P. Cana-de-açúcar: a melhor alternativa para conversão da energia solar e fóssil em etanol. Econ. Energia, v. 2, n. 59, p.27-33, 2006.

ARRUDA, J. S.; LOPES, N. S.; BACARIN, M. A. Nodulação e fixação do dinitrogênio em soja tratada com sulfentrazone. Pesq. Agropec. Bras., v. 36, n. 2, p. 325-330, 2001.

BARROSO, C. B.; PEREIRA, G. T.; NAHAS, E. Solubilization of cahpo4 and alpo4 by Aspergillus niger in culture media with different carbon and nitrogen sources. Braz. J. Microbiol., v. 37, n. 4, p. 434-438, 2006.

BERTIN, C.; YANG, X.; WESTON, L. A. The role of root exudates and allelochemicals in the rhizosphere. Plant Soil, v. 256, n. 1, p. $67-83,2003$.

BRAGA, J. M.; DEFELIPO, B. V. Determinação espectrofotométrica de fósforo em extratos de solos e plantas. R. Ceres, v. 21, n. 113, p. 73-85, 1974.

BUNEMANN, E. K.; SCHWENKE, G. D.; van ZWIETEN, L. Impact of agricultural inputs on soil organisms - a review. Austr. J. Soil Res., v. 44, n. 4, p. 379-406, 2006.

COMISSÃO DE FERTILIDADE DO SOLO DO ESTADO DE MINAS GERAIS - CFSEMG. Recomendações para o uso de corretivos e fertilizantes em Minas Gerais $-\mathbf{5}^{\text {a }}$ aproximação. Viçosa, MG: Universidade Federal de Viçosa, 1999. 359 p

CHIEN, S. H.; MENON, R. G. Factors affecting the agronomic effectiveness of phosphate rock for direct application. Fert. Res., v. 41, n. 2, p. 227-234, 1995.

CHRISTOFFOLETI, P. J. et al. Carfentrazone-ethyl aplicado em pós-emergência para o controle de Ipomea spp. e Commelina benghalensis na cultura da cana-de-açúcar.

Planta Daninha, v. 24, n. 1, p. 83-90, 2006.

COLOMBO, S. Um desafio para o Brasil. J. USP, v. 22, n. 784 , p. $4-5,2006$

DAS, A. C.; DEBNATH, A.; MUKHERJEE, D. Effect of the herbicides oxadiazon and oxyfluorfen on phosphates solubilizing microorganisms and their persistence in rice fields. Chemosphere, v. 53, n. 2, p. $217-221,2003$.

EMPRESA BRASILEIRA DE PESQUISA AGROPECUÁRIA - EMBRAPA. Centro Nacional de Pesquisa Agropecuária de Solos. Sistema brasileiro de classificação de solos. Rio de Janeiro: 2006. 412 p. 
EMPRESA BRASILEIRA DE PESQUISA

AGROPECUÁRIA - EMBRAPA. 2007. Disponível em:

$<$ http://www.embrapa.gov.br/noticias/artigos/>. Acesso em:

10 dez. 2008.

FERREIRA, E. A. et al. Sensibilidade de cultivares de canade-açúcar à mistura trifloxysulfuron-sodium + ametryn.

Planta Daninha, v. 23, n. 1, p. 93-99, 2005.

GALON, L. Tolerância de genótipos de cana-de-açúcar a herbicidas. 2008. 88f. Tese (Doutorado em Fitotecnia) Universidade Federal de Viçosa, Viçosa-MG, 2008.

ISLAM, K. R.; WEIL, R. R. Microwave irradiation of soil for routine measurement of microbial biomass carbon. Biol. Fert. Soils, v. 27, n. 4, p. 408-416, 1998.

JAKELAITIS, A. et al. Atividade microbiana e produção de milho (Zea mays) e de Brachiaria brizantha sob diferentes métodos de controle de plantas daninhas. Planta Daninha, v. 25, n. 1, p. 71-78, 2007.

MAHÍA, J. et al. Microbial biomass and C mineralization in agricultural soils as affected by atrazine addition. Biol. Fert. Soils, v. 45, n. 1, p. 99-105, 2008.

MASSENSSINI, A. M et al. Atividade de isolados bacterianos solubilizadores de fosfato na presença de formulações comerciais de glyphosate. Planta Daninha, v. 26, n. 4, p. 815-823, 2008.

MOREIRA, F. M. S.; SIQUEIRA, J. O. Microbiologia e bioquímica do solo. 2.ed. Lavras, MG: Universidade Federal de Lavras, 2006. 729 p.

MORENO, J. L. et al. Effects of atrazine on microbial activity in semiarid soil. Appl. Soil Ecol., v. 35, n. 1, p. 120-127, 2007.

NAHAS, E.; FORNASIERI, D. J.; ASSIS, L. C. Resposta a inoculação de fungo sulubilizador de fósforo em milho. Sci. Agric., v. 51, n. 3, p. 463-469, 1994.

NAUTIYAL, C. S. An efficient microbiological growth medium for screening phosphate solubilizing microorganisms. FEMS Microbiol. Lett., v. 170, n. 1, p. 265-270, 1999.

NOVAIS, R. F.; SMYTH, T. J. Fósforo em solo e planta em condições tropicais. Viçosa, MG: Universidade Federal de Viçosa, 1999. 268 p.

PIRES, F. R. et al. Rhizospheric activity of potentially phytoreme-diative species for tebuthiuron-contaminated soil. R. Bras. Ci. Solo, v. 29, n. 4, p. 627-634, 2005.

PRAMANIK, M. H. R. et al. Effect of temperature and photoperiod on phytotoxic root exudates of cucumber (Cucumis sativus) in hydroponic culture. J. Chem. Ecol., v. 26, n. 8, p. 1953-1967, 2000.
PROCÓPIO, S. O. et al. Manejo de plantas daninhas na cultura da cana-de-açúcar. Viçosa, MG: Universidade Federal de Viçosa, 2003. 150 p.

REIS, M. R. et al. Ação de herbicidas sobre microrganismos solubilizadores de fosfato inorgânico em solo rizosférico de cana-de-açúcar. Planta Daninha, v. 26, n. 2, p. 333-341, 2008a.

REIS, M. R. et al. Atividade microbiana em solo cultivado com cana-de-açúcar após aplicação de herbicidas. Planta Daninha, v. 26, n. 2, p. 323-331, 2008b.

RODRIGUES, B. N.; ALMEIDA, F. R. Guia de herbicidas. 5.ed. Londrina: Edição dos Autores, 2005. 591 p.

RODRÍGUEZ, H.; FRAGA, R. Phosphate solubilizing bacteria and their role in plant growth promotion. Biotechnol. Adv., v. 17, n. 4-5, p. 319-339, 1999.

ROSSI, C. V. S.; ALVES, P. L. C. A.; MARQUES JUNIOR, J Mobilidade do sulfentrazone em Latossolo Vermelho e em Chernossolo. Planta Daninha, v. 23, n. 4, p. 701-710, 2005.

SANTOS, J. B. et al. Efeitos de diferentes formulações comerciais de glyphosate sobre estirpes de Bradyrhizobium. Planta Daninha, v. 22, n. 2, p. 293-299, 2004

SANTOS, J. B. et al. Atividade microbiana do solo após aplicação de herbicidas em sistemas de plantio direto e convencional. Planta Daninha, v. 23, n. 4, p. 683-691, 2005.

SHAW, L. J.; BURNS, R. G. Enhanced mineralization of [U-14C] 2,4-dichlorophenoxy- acetic acid in soil from the rhizosphere of Trifolium pretense. Appl. Environ.

Microbiol., v. 70, n. 8, p. 4766-4774, 2004.

SINDICATO NACIONAL DA INDÚSTRIA DE PRODUTOS PARA DEFESA AGRÍCOLA - SINDAG.

2008. Disponível em: $<\mathrm{http} / / /$ www.sindag.com.br $>$. Acesso em: 20 dez. 2008.

SILVA FILHO, G. N.; NARLOCH, C.; SCHARF, R. Solubilização de fosfatos naturais por microrganismos isolados de cultivos de Pinus e Eucalyptus de Santa Catarina Pesq. Agropec. Bras., v. 37, n. 6, p. 847-854, 2002.

SILVA FILHO, G. N.; VIDOR, C. Atividade de microrganismos solubilizadores de fosfatos na presença de nitrogênio, ferro, cálcio e potássio. Pesq. Agropec. Bras., v. 36, n. 12 , p. $1495-1508,2001$.

SILVA, A. A. et al. Herbicidas: classificação e mecanismo de ação. In: SILVA, A. A.; SILVA, J. F. (Eds.). Tópicos em manejo de plantas daninhas. Viçosa, MG: Universidade Federal de Viçosa, 2007. p. 83-148. 
VANCE, E. D.; BROOKES, P. C.; JENKINSON, D. S. An extraction method for measuring soil microbial biomass C.Soil. Biol. Biochem., v. 19, n. 6, p. 703-707, 1987.

VASSILEV, N.; VASSILEVA, M. Biotechnological solubilization of rock phosphates on media containing agroindustrial wastes. Appl. Microbiol. Biot., v. 61, n. 5, p. $435-440,2003$

VIEIRA, R. F.; SILVA, C. M. M. S.; SILVA, A. P. D. Soil microbial biomass $\mathrm{C}$ and symbiotic processes associated with soybean after sulfentrazone herbicide application. Plant Soil v. 300, n. 1, p. $95-103,2007$
VIVIAN, R. et al. Persistência de sulfentrazone em Argissolo Vermelho-Amarelo cultivado com cana-de-açúcar. Planta Daninha, v. 24, n. 4, p. 741-750, 2006.

YANG, Y. et al. Characteristics and mechanisms of phosphate adsorption on dewatered alum sludge. Separ. Purif.

Technol., v. 51, n. 2, p. 193-200, 2006

ZABALOY, M. C. et al. An integrated approach to evaluate the impacts of the herbicides glyphosate, 2,4-D and metsulfuron-methyl on soil microbial communities in the Pampas region, Argentina. Appl. Soil Ecol., v. 40, n. 1, p. 1-12, 2008. 